\title{
Mercantilização do ensino superior, educação a distância e Serviço Social
}

\author{
Larissa Dahmer Pereira \\ Universidade Federal Fluminense (UFF)
}

\section{Mercantilização do ensino superior, educação a distância e Serviço Social}

Resumo: Este trabalho objetiva analisar o significado do processo de mercantilização do ensino superior, sua expansão entre os anos 1980 e 1990 e, particularmente, a modalidade de educação a distância. Inicialmente, analisa a transformação da educação de direito em serviço comercial, a partir dos anos 1970, inserida em um contexto mundial de crise de acumulação capitalista. Posteriormente, discorre sobre o aprofundamento da mercantilização da educação superior no Brasil, a partir dos anos 1990, e a consequente expansão da modalidade, como parte do reordenamento das funções do Estado, inserida em um contexto de contrarreforma. Em seguida, apresenta o surgimento dos cursos de Serviço Social em EaD, problematizando como esta nova modalidade de ensino pode impactar o perfil profissional defendido pelas Diretrizes Curriculares da Associação Brasileira de Ensino e Pesquisa em Serviço Social (ABEPSS). Com este texto, pretende-se apontar algumas questões e novos desafios para a formação profissional em Serviço Social.

Palavras-chave: mercantilização, ensino superior, educação a distância, formação profissional, Serviço Social.

\section{Commodification of Higher Education, Distance Education and Social Work}

Abstract: The purpose of this paper is to analyze the meaning of the process of commodification of higher education, its expansion in the 1980s and 1990s and particularly, the modality of distance education. It first analyzes the transformation of education from a right to a commercial service beginning in the 1970s, inserted in a global context of crisis in capitalist accumulation. It looks at the depth of commodification of higher education in Brazil, since the 1990s and the consequent expansion of this mode, as part of the re-ordering of the functions of the State, inserted in a context of counter-reform. The paper then presents the rise of Social Work courses in Distance Education, analyzing how this new mode of education can impact the professional profile defended by the Curriculum Guidelines of the Brazilian Association of Education and Research in Social Service (ABEPSS). The paper intends to raise some new issues and challenges for professional education in Social Work.

Key words: commodification, higher education, distance education, professional education, Social Work. 


\section{Educação superior, de direito a "serviço"}

O século 20, particularmente o pós-1945, presenciou a consolidação do estágio monopolista do capital, a luta de classes acirradas, a passagem de um Estado em sentido estrito para um Estado ampliado e o processo de socialização da política ${ }^{1}$. Neste contexto, a política educacional acompanhou o movimento das políticas sociais em geral - de alargamento da cidadania $^{2}$ - e desenvolveu diversos níveis de educação.

Portanto, com a instituição do padrão fordistakeynesiano e de uma cultura urbano-industrial, o amplo desenvolvimento do aparelho escolar durante a segunda metade do século 20 respondeu às exigências produtivas de um maior nível educacional, para a formação de um homem de novo tipo, adaptável ao padrão de produção e consumo em massa e imunizado do espectro do comunismo em tempos de Guerra Fria. Por outro lado, tal ampliação respondeu também às lutas da classe trabalhadora pela socialização do conhecimento gerado pela humanidade. Desde então, é possível constatar um veloz crescimento do aparelho escolar em todos os níveis, ressaltando-se a "explosão" de matrículas no nível superior: de 13 milhões de estudantes, em 1960 para 82 milhões, em 1995 (UNESCO, 1999a; 1999b). Em 2006, o número de estudantes universitários no mundo contabilizava 110,7 milhões, de acordo com o relatório sobre a situação do ensino superior no mundo (UNIVERSIA, 2005).

Para a compreensão deste abrupto crescimento, consideram-se as transformações societárias ocorridas no pós-1970, decorrentes da crise do padrão de acumulação capitalista erigido no pós-guerra (HARVEY, 1992). Conhecido pela "crise do petróleo" de 1973, tal fenômeno, mais do que uma crise energética, significou uma dificuldade intensa de realização do ciclo de acumulação capitalista, até então baseado na máxima fordista: produção em massa para um consumo/mercado de massa e nas políticas anticíclicas keynesianas. Nas décadas de 1960 e 1970, ainda no contexto geopolítico de "Guerra Fria", os mercados - europeu e japonês, principalmente encontravam-se em fase de saturação, enquanto a ideologia desenvolvimentista impunha-se aos países periféricos, particularmente aos da América Latina.

Como formas de enfrentamento da crise - sem alterar logicamente o status quo - buscou-se um tripé de "soluções", com processos de reestruturação produtiva, liberalização do fluxo dos capitais financeiros e a retração dos Estados nacionais no que concerne ao provimento dos direitos sociais conquistados ao longo do século 20.

Tal processo, associado à derrocada do mundo soviético - com a emblemática queda do Muro de Berlim (1989) -, trouxe um amplo espaço para a movimentação do capital em todos os espectros da vida social.
Se até a década de 1960 constatava-se um relativo acesso da classe trabalhadora aos bens sociais através de políticas sociais desmercadorizantes, a partir dos anos 1970 houve uma intensa disputa, entre capital e trabalho, pelo uso do "fundo público" (OLIVEIRA, 1998). O "cabo de guerra", contudo, pendeu favoravelmente para os detentores dos meios de produção, visto que os processos de reestruturação produtiva resultaram em altas taxas de dessindicalização, precarização das condições de trabalho, desemprego estrutural e, portanto, fragilização dos tradicionais processos organizativos daqueles que vivem do seu trabalho (ANTUNES, 1997).

Os anos 1980 inauguraram, através dos governos Tatcher, na Inglaterra, e Reagan, nos EUA, a avalanche demolidora do ideário neoliberal que, ressurgente das cinzas, espalhou pelos quatro cantos do mundo sua cartilha homogeneizadora: ajuste fiscal, repressão aos sindicatos, diminuição drástica e/ ou corte nos investimentos sociais, liberalização dos fluxos financeiros por todo o globo, exaltação ao individualismo e alastramento da cultura pós-moderna (ANDERSON, 1998).

No contexto de aprofundamento do projeto neoliberal, políticas sociais como saúde, previdência e educação - antes implementadas através da ação estatal e com cunho universal - foram relegadas a último plano, com ações focalistas dos Estados e, ao mesmo tempo, ampla abertura para a exploração mercadológica de tais necessidades sociais. Saúde, previdência e educação passaram a ser concebidas como "serviços", cujos objetivos pautam-se na lógica mercantil e têm como finalidade última a obtenção do lucro. Assim, a figura do cidadão reposiciona-se para a de "cidadão-consumidor" (caso tenha renda para consumir planos de saúde, previdência e mensalidades escolares) e "cidadão-pobre" (MOTA, 1995), alvo das políticas focalistas estatais e/ou "beneficiário" de projetos sociais realizados pelo "Terceiro Setor"3, majoritariamente com recursos públicos.

No quadro atual, a existência de políticas sociais universalizantes e o acesso à educação pública - tradutores da concreticidade dos direitos sociais e com uma explícita dimensão civilizatória, produto das lutas sociais ao longo dos séculos 19 e 20 - torna-se extremamente limitada. Constata-se a abertura da educação superior como um amplo e lucrativo campo de exploração para grandes grupos empresariais, corroborada com dados da UNESCO (1999b).

Contudo, a expansão mercantilizada do ensino superior - já em curso e concentrada nos países periféricos e $\mathrm{EUA}^{4}$ - precisa ser sustentada por elementos ideológicos que justifiquem tal processo e anulem a concepção de direito à educação pública superior, agora transmutada em um "serviço".

A primeira base ideológica que sustenta a necessidade premente de expansão do ensino superior é a 
ideia de "aldeia global", isto é, em um mundo inexoravelmente globalizado, a educação é o meio principal dos países periféricos a ela se integrarem (LEHER, 1998).

Outro elemento ideológico sustentador da educação como meio para resolver os problemas da humanidade - sem, obviamente, questionar o sistema capitalista mundial e a sua lógica de acumulação, gerando centralização da riqueza relativamente à socialização da miséria - é a defesa, por parte dos inúmeros documentos dos organismos internacionais, de que a difusão da educação superior deve se dar fundamentalmente via ensino a distância através do uso das Tecnologias de Informação e Comunicação (TICs).

Lima (2007) analisa minuciosamente a difusão das seguintes noções:

a) "sociedade pós-capitalista" ou "capitalismo informacional", disseminada por Peter Drucker;

b) revolução técnico-científica e a configuração de uma "sociedade informática", de Adam Schaff;

c) "sociedade em rede" e a "galáxia da internet", de Manuel Castells; e

d) "revolução informacional", de Jean Lojkine.

Tais conceitos apresentam em comum a ideia de que estaríamos em uma sociedade na qual o principal fator de produção seria o conhecimento. Portanto, todos os indivíduos teriam a possibilidade de possuírem o próprio meio de produção, o que dependeria da aquisição de conhecimentos centrada no indivíduo. Logo, o raciocínio é de que estaríamos passando por uma verdadeira revolução, em direção a uma "sociedade pós-capitalista", "informática", interligada em redes, isto é, uma verdadeira "revolução informacional" (LIMA, 2007, p. 27/49).

Como é possível observar, tais formulações apagam a existência de uma sociedade partida em classes sociais - daqueles detentores e não detentores dos meios de produção - e indica a tecnologia como a solução para os problemas atuais, criando, assim, um verdadeiro fetiche tecnológico. Tal fetichismo baseiase no pressuposto da necessidade de disseminação do uso das TICs, o que traria, por si só, a integração dos países à “aldeia global", velando também a existência da divisão internacional do trabalho e das desigualdades regionais, intra e entre países (LIMA, 2007).

Segundo Lima e Martins (2005), outro elemento ideológico fundamental, que fortalece politicamente as noções acima delineadas, é o projeto da "Terceira Via", cujo objetivo é, como um movimento de reação à contra-hegemonia, fundar uma nova ideologia, pautada na permanência da ordem capitalista e na concepção da sociedade civil como espaço de colaboração e ajuda mútua, num explícito aclassismo.

A “Terceira Via”, segundo os autores supracitados, afirma-se como um projeto para além da esquerda e da direita e, comungando das ideias liberais, defende o mercado livre e a posição da sociedade civil como "parceira", ativa, do Estado no fomento à coesão social. Este Estado, reformado, deve impulsionar uma nova cultura cívica através da renovação organizativa da sociedade civil, do trabalho voluntário e do empreendedorismo social, no combate às mazelas sociais. Nesta proposta cabe à educação superior o papel fulcral de formar futuros profissionais para atuar na sociedade civil. Tais profissionais devem, contudo, ser formados no que Chaui (1999) analisa como a universidade da fase tardia do capital, a "universidade operacional": com um processo de formação esvaziado, reduz suas atividades ao treinamento e à "reciclagem" e anula a possibilidade da crítica ao status quo.

Assim, em um processo dialético, o ensino superior, ao mesmo tempo em que é reconfigurado no novo contexto de crise do capitalismo tardio como um espaço mercantilizado - para as necessidades expansionistas em tempos de crise do capital -, é ele próprio um elemento fundamental para a disseminação da ideologia da "Terceira Via", através da formação massificada de intelectuais colaboracionistas à ordem do capital. A EaD configura-se, portanto, como uma via extremamente lucrativa para a expansão capitalista e a formação de intelectuais necessários à ordem burguesa, com a criação das primeiras Universidades Abertas na década de 1970 e sua expansão mundial a partir de então.

\section{Educação superior brasileira: aprofunda- mento da mercantilização e expansão da EaD no pós-1990}

O processo antes delineado, produzido em âmbito global, traduziu-se no Brasil particularmente ao longo de toda a década de 1990, monitorado pelos organismos internacionais ${ }^{5}$ e pela ciência, com a adesão e o direcionamento por parte da burguesia brasileira. Recém-saída de uma longa ditadura militar e com uma nova Constituição Federal promulgada através de ampla participação popular, a burguesia brasileira organizou um amplo processo de contrarreforma, atrelado às novas exigências do capital mundializado. Assim, desde o governo Collor, Itamar e, de forma consolidada, nos governos Cardoso e Lula, a Constituição Federal de 1988 foi mantida na letra da lei, mas desmantelada no cotidiano da nação, através de fortes processos de ajuste fiscal, privatização do patrimônio nacional, abertura desenfreada do mercado brasileiro e de contrarreforma do aparelho estatal $^{6}$, num ofensivo processo de "desertificação neoliberal"' (ANTUNES, 2004).

Para realizar tamanha transformação na sociedade brasileira, foi preciso preparar um sólido terre- 
no ideológico, sustentado pelo que Mota (1995) denominou de "cultura da crise". Esta tem como premissa o que Bresser Pereira (1997, p. 3) afirma: "tornou-se cada vez mais claro que a causa básica da grande crise dos anos [19]80 é uma crise do Estado [...]." Tal perspectiva aponta que a causa da crise é resultante de um mau gerenciamento do Estado - e não um processo decorrente da crise de acumulação capitalista. O Estado é definido como ineficiente, burocrático, sendo urgente reformá-lo, o que implica colocá-lo como mero financiador e gerenciador de políticas, desresponsabilizando-o de uma série de funções e "filtrando" a possibilidade de controle social por parte da sociedade civil.

Em 1995, um plano estratégico para uma "reforma emergencial do aparelho do Estado" foi enviado ao Congresso Nacional pela Presidência da República, com objetivo de transformação da "administração pública brasileira burocrática em administração pública gerencial"'. O referido plano define a educação - e demais áreas sociais - como uma atividade não exclusiva do Estado e indica que a produção e execução dos serviços sociais devem ficar sob a responsabilidade das instituições privadas ou públicas não estatais.

A proposta que insere a educação como atividade não exclusiva do Estado abre precedentes para a desresponsabilização do Estado, a sua privatização e execução por instituições "não estatais", o que foi concretizado ao longo dos anos 1990 e permanece em consolidação na entrada do século 21. Através da operacionalização de um verdadeiro processo de ressignificação dos conceitos de público, privado e estatal, no plano político, efetivou-se, no plano jurídico-formal, o redesenho do Estado brasileiro, e, particularmente, da educação superior. Assim, o Estado brasileiro, ao longo da década de 1990, realizou ativamente a sua missão educadora: abriu largos caminhos para o setor privado, liberalizando a área social, e, ao mesmo tempo, efetivou ações concretas de construção de uma "nova pedagogia da hegemonia", pautada no aclassismo e no objetivo de construir uma participação política colaboracionista, redefinindo o padrão de politização fordista (NEVES, 2005).

Para a aceitação da desresponsabilização do Estado frente à "questão social" e a transferência de tal responsabilidade para as "comunidades", é fundamental a incorporação da ideologia da "Terceira Via" em todas as classes sociais, o que demanda a formação de intelectuais ${ }^{9}$ em todos os níveis educacionais, que sejam, no plano ético-político, colaboradores e, no plano econômico-corporativo, estejam munidos da ideologia liberal do empreendedorismo.

Assim, o ensino superior constitui-se como um veio extremamente lucrativo para o capital e, ao mesmo tempo, destaca-se pelo seu papel na disseminação ideológica da sociabilidade colaboracionista, através da formação de intelectuais colaboradores e empreendedores, sob a ótica do capital.

A década de 1990 e o início do século 21 registraram um franco processo de expansão e de mercantilização do ensino superior, validado e incentivado pelos governos, de Cardoso a Lula, pautados no pressuposto de que a educação é um "bem público", sendo, portanto, um direito de instituições públicas e privadas oferecerem seus serviços educacionais à população. Cabe ao Estado a partilha dos recursos públicos: naturaliza-se a entrega de verbas públicas para o setor privado e, ao mesmo tempo, o financiamento privado para as IES públicas, numa explícita diluição de fronteiras entre o público e o privado ${ }^{10}$.

A presença do setor privado na educação superior mantém-se predominante: o Censo da Educação

Superior de 2007 informa a existência de 2.281 IES, sendo $89 \%$ de natureza privada. Há uma predominância, quanto à organização acadêmica, de instituições não universitárias, isto é, instituições que não precisam realizar pesquisa, somente transferir conhecimento: $86,7 \%$ das IES encontram-se registradas como faculdades, enquanto as universidades ${ }^{11} \mathrm{e}$ centros universitários respondem por $8 \%$ e 5,3\%. Cabe salientar que os centros universitários também não são obrigados à realização de pesquisa, $\mathrm{o}$ que faz as IES não universitárias representarem mais de $90 \%$ do total das IES existentes no país (BRASIL, 2009a).

Ainda sobre a organização acadêmica, é clara a preferência do setor privado por atividades menos custosas e, logo, mais lucrativas: o censo de 2007 mostra que " [...] o maior número de faculdades $(92,5 \%)$ e de centros universitários $(96,7 \%)$ está vinculado ao setor privado, enquanto as universidades estão distribuídas em proporção aproximada entre o setor público e o privado, 52,5\% e 47,5\%, respectivamente" (BRASIL, 2009a). 
Outro dado que ratifica o processo de expansão do setor privado diz respeito às matrículas nas IES: o Censo da Educação Superior de 2004 indicava que $71,7 \%$ das matrículas registradas pertenciam ao setor privado (BRASIL, 2005). O censo de 2007 destaca que a maior parte das matrículas, $74,6 \%$ (3,7 milhões), pertence às instituições privadas, que registraram aumento de 5\% em relação ao ano anterior. As demais matrículas estão computadas nas IES federais, estaduais e municipais, correspondendo a $12,6 \%, 9,9 \%$ e $2,9 \%$ do total, respectivamente (BRASIL, 2009b).

Os dados antes expostos corroboram a tese da continuidade da expansão do ensino superior, via setor privado, também no governo Lula ${ }^{12}$. Contudo, se este governo é marcado por continuidades em relação ao governo Cardoso - principalmente no que diz respeito à política econômica de ajuste fiscal - é necessário apreender as suas peculiaridades que reforçam, com um verniz democratizante, o processo de mercantilização da educação superior. $\mathrm{O}$ discurso governamental baliza-se pela defesa da expansão da educação superior, isto é, a democratização do acesso ao nível superior de ensino, utilizando-se, para tanto, dos seguintes meios:

a) participação do setor privado presencial, através de ampla isenção fiscal, possibilitada pelo Programa Universidade para Todos (ProUni) $)^{13}$;

b) participação dos setores público e privado de ensino a distância $(\mathrm{EaD})$;

c) ampla reestruturação do sistema público de ensino, por meio do Programa de Apoio a Planos de Reestruturação e Expansão das Universidades Federais (Reuni);

d) reforço, na universidade pública, da lógica da mercantilização, através das parcerias público-privadas.

A intenção deste trabalho não é realizar uma análise minuciosa de cada ação governamental voltada para o ensino superior, visto que o objetivo é centrarse na problematização do surgimento de cursos de graduação em Serviço Social na modalidade EaD. Porém, é fundamental destacar que o discurso de democratização do ensino superior apresentado pelo governo Lula vela, na realidade, um processo de certificação e não de formação qualificada de novos profissionais. Não se nega a necessidade de ampliação do acesso ao ensino superior, o que no Brasil é uma demanda latente ${ }^{14}$. Contudo, reitera-se que o acesso deve ser um direito social, isto é, não mercantilizado. A via escolhida pela política governamental ${ }^{15}$, como o próprio INEP apresenta em seu Censo (BRASIL, 2009b), mantém o setor privado como central na oferta de vagas no nível superior de ensino, majoritariamente em IES não universitárias, passando ao largo da dimensão da pesquisa, em cursos mais lucrativos ao empresariado do ensino.
A oferta de cursos na modalidade EaD vem crescendo no país, embora ainda represente $7 \%$ do número de matrículas no ensino superior (369.766 matrículas, em 2007) e tenha uma baixa relação candidato/vaga $(0,35)$. O crescimento pode ser verificado em relação ao ano de 2006, quando a $\mathrm{EaD}$ participava com $4,2 \%$ do número de matrículas, o que se ampliou em 2007, para 7\% (BRASIL, 2009b).

O setor público oferece cursos de graduação na modalidade $\mathrm{EaD}$, principalmente com o enfoque na formação de professores (licenciaturas). Através da Universidade Aberta do Brasil (UAB) - criada em 2005, no governo Lula, e voltada para a formação de professores através de cursos a distância, oferecidos por instituições públicas (municipais, estaduais e federais) - são ofertadas as vagas públicas. Há diversas modalidades de cursos oferecidos - extensão, sequencial, licenciatura, bacharelado, tecnólogo, especialização e mestrado -, sendo a maioria de licenciatura (94), seguindo-se os cursos de especialização (44) e bacharelado (23) (BRASIL, 2009a).

Quanto à certificação, os diplomas têm a mesma validade que os de cursos presenciais, de acordo com o decreto presidencial n. 5.622, de 19 de dezembro de 2005 (BRASIL, 2005). O ingresso ocorre através de vestibular e o ensino é gratuito ${ }^{16}$. Em relação ao número de vagas, o sistema UAB (BRASIL, 2009c, online) informa que em 2007 " [...] atingiu um total de 291 polos educacionais, em pleno funcionamento, possibilitando com isso a abertura de 46 mil vagas de ensino superior."

O setor privado tem grande participação na oferta de cursos na modalidade EaD: de acordo com os dados do Censo da Educação Superior, 97 instituições ofereceram, em 2007, 408 cursos de graduação na modalidade $\mathrm{EaD}$, sendo 260 (63,7\%) de caráter privado (BRASIL, 2009a). Portanto, apreende-se que as empresas educacionais interessam-se bastante por este "filão", que vai para além das licenciaturas ${ }^{17}$, e explora a abertura de cursos, geralmente, concentrados na área de Humanidades - devido aos baixos custos -, dentre eles podemos destacar o curso de Serviço Social.

\section{Surgimento dos cursos a distância de Serviço Social}

No tocante ao Serviço Social brasileiro, observase que, historicamente, o assistente social ocupou, na divisão sociotécnica do trabalho, uma função intelectual colaboracionista com a concepção de mundo burguesa. Esta profissão surge nos anos 1930 - inicialmente através do movimento de Ação Católica e com predominante influência franco-belga - e é institucionalizada como profissão na segunda metade dos anos 1940 e na década de 1950, com a criação de grandes instituições assistenciais e já sob for- 
te influência norte-americana. Todavia, somente no pós-1964, com a contraditória política assistencial e repressiva dos governos militares, o mercado de trabalho para os assistentes sociais torna-se relevante. Neste contexto, há uma ampliação dos cursos de Serviço Social, inseridos em ambientes universitários e escolas isoladas ${ }^{18}$. No entanto, o direcionamento conservador permanece até a década de 1970 e só será contestado no bojo das lutas pela abertura política no país ${ }^{19}$, configurando-se, desde então, um processo de renovação profissional ${ }^{20}$.

O processo de renovação profissional - possibilitado pela laicização da profissão e pela sua inserção na universidade proporcionadas contraditoriamente pela autocracia burguesa - desencadeou os seguintes movimentos internos ao Serviço Social, apontados por Paulo Netto (1996b): a) a construção de um pluralismo teórico, ideológico e político profissional; b) a crescente diferenciação das concepções profissionais; c) a interlocução acadêmica e cultural do Serviço Social; d) segmentos de profissionais constituíram-se enquanto uma vanguarda, voltada para a investigação e a pesquisa. $\mathrm{O}$ seu aperfeiçoamento foi caracterizado pelas revisões, em 1993, do Código de Ética profissional de 1986, e da Lei de Regulamentação da Profissão, do currículo de 1982, entre 1994 e 1996, e pela aprovação das Diretrizes Curriculares da Associação Brasileira de Ensino e Pesquisa em Serviço Social (ABESS/CEDEPSS, 1997).

A aprovação das Diretrizes contou com a participação de 67 unidades de ensino filiadas à ABEPSS: ressalte-se que até 1994 existiam 74 unidades de ensino em Serviço Social ${ }^{21}$ : portanto, a participação dos cursos nos debates de revisão curricular equivaleu a $90,5 \%$, o que pode ser considerado como uma participação bastante satisfatória.

Contudo, desde a aprovação das Diretrizes Curriculares da ABEPSS, o número de cursos de Serviço Social no país aumentou consideravelmente. Cabe destacar o crescimento abrupto de cursos de Serviço Social no país, nos governos Lula: de 332 cursos existentes, mais $205(61,7 \%)$ foram autorizados a funcionar entre os anos de 2003 e 2009, sendo $91,7 \%$ de natureza privada ${ }^{22}$.

Ao analisarmos a oferta de vagas nos 332 cursos de Serviço Social existentes no país, é possível verificar que a participação da modalidade educação a distância atinge mais de 50\%.
Outro aspecto que revela o interesse empresarial no curso de Serviço Social é a natureza jurídica das IES ofertantes de vagas na modalidade EaD: das onze IES que oferecem cursos nesta modalidade, dez são de natureza privada. Somente uma é pública estadual, porém enquadra-se na categorização de fundação pública de direito privado.

A análise da política educacional no período 1995 a 2002, bem como a análise e caracterização dos cursos de Serviço Social, já foi realizada pela autora, que constatou:

Em face do quadro delineado, é possível afirmar que o Serviço Social sofreu um verdadeiro processo 'explosivo' de crescimento de suas unidades de ensino, esmagadoramente privadas e inseridas em instituições não universitárias. Assim, o empresariado do ensino passou a identificar o curso de Serviço Social como mais um curso explorável na área de Humanas. Isto significou a efetiva laicização e o puro empresariamento do ensino em Serviço Social, especialmente após 1995, articulando-se tal movimento do empresariado com o movimento mais amplo do Estado brasileiro de incentivo à expansão do ensino superior via setor privado e não confessional. Assim, a criação de ESSs no Brasil relaciona-se com o movimento mais amplo de necessidade de realização do capital, mas também de formação de intelectuais difusores de uma ideologia colaboracionista, consensual, sob a ótica e as necessidades do capital (PEREIRA, 2008a, p. 194).

Pouco se conhece sobre as condições concretas da formação profissional nestes novos cursos, criados a partir de 2003, e menos ainda nos cursos cuja modalidade de ensino é a distância, pois se trata de um fenômeno extremamente novo na profissão: os cursos na modalidade a distância foram autorizados a partir de 2004 e começaram o funcionamento efetivo a partir do ano de 2006.

Contudo, como é de largo conhecimento, os cursos na área de Humanas são os "preferidos" pelos empresários do ensino, pois não exigem grande investimento - como, por exemplo, em laboratórios e insumos tecnológicos - e possibilitam um lucrativo e rápido retorno.

\section{Tabela 1 - Vagas de Serviço Social distribuídas segundo modalidade de ensino}

\begin{tabular}{|ccc|}
\hline Modalidade de ensino & Número de vagas oferecidas nos cursos de Serviço Social & $\%$ \\
\hline Presencial & $38.532^{23}$ & 45,3 \\
\hline EaD & 46.620 & 54,7 \\
\hline Total de vagas & 85.152 & 100,0 \\
\hline
\end{tabular}

Fonte: elaboração da autora, a partir do Cadastro do INEP (BRASIL, 2009). 
Do ponto de vista didático-pedagógico, o ensino a distância reconfigura completamente a formação, visto que descentra a figura do professor e cria um novo sujeito: o "tutor". Outro ponto fundamental diz respeito à nula vivência acadêmica do aluno: sua formação restringe-se ao ensino "tutorial", não abarcando as dimensões fundamentais da pesquisa e extensão. Consideremos ainda a não proximidade deste aluno com movimentos coletivos, como o movimento estudantil.

A hipótese é, portanto, que a formação profissional dos novos assistentes sociais, formados via $\mathrm{EaD}$, será radicalmente diferente da propugnada pelas Diretrizes Curriculares da ABEPSS (ABESS/CEDEPSS, 1997), o que reconfigurará completamente o mercado de trabalho em Serviço Social e trará complexos desafios para as entidades da categoria ${ }^{24}$.

\section{Considerações finais}

A problematização aqui apresentada propõe-se a ser um passo inicial para um maior conhecimento sobre o significado da expansão do ensino superior via EaD, o que possibilitará um maior embasamento para o estudo do processo formativo nos cursos de graduação em Serviço Social a distância.

Considera-se que o desenvolvimento posterior da presente pesquisa contribuirá para um maior conhecimento sobre as condições reais de formação nos cursos de graduação a distância em Serviço Social do país, apreendendo como, concretamente, vem se desenvolvendo a formação destes profissionais.

A partir de tal diagnóstico, será possível não somente indicar os limites atuais de uma formação profissional de qualidade mas também apontar as possibilidades de enfrentamento de tais limitações. Esse procedimento contribuirá para o fortalecimento da direção impressa nas Diretrizes Curriculares ABEPSS e, logo, fomentará as entidades da categoria com dados que auxiliarão na tomada de decisões quanto às ações necessárias relativas à formação profissional.

Portanto, considera-se que a pesquisa sobre os cursos de Serviço Social na modalidade a distância é de fundamental importância para apreendermos de forma consistente as características da expansão do ensino em Serviço Social no país e quais as suas implicações para a formação profissional dos novos assistentes sociais no século 21 .

\section{Referências}

ANDERSON, P. Balanço do neoliberalismo. In: SADER, E.; GENTILLI, P. (Org.). Pós-neoliberalismo - as políticas sociais e o Estado democrático. São Paulo: Paz e Terra, 1998.
ANTUNES, R. et al. Neoliberalismo, trabalho e sindicatos. Reestruturação produtiva no Brasil e na Inglaterra. São Paulo: Boitempo, 1997. (Coleção Mundo do Trabalho).

. A desertificação neoliberal no Brasil (Collor, FHC e Lula). Campinas: Autores Associados, 2004.

ABESS/CEDEPSS. Diretrizes Gerais para o curso de Serviço Social (com base no currículo mínimo aprovado em Assembleia Geral Extraordinária de 8 de novembro de 1996). Cadernos ABESS, n. 7, Edição Especial - Formação Profissional - trajetórias e desafios. São Paulo: Cortez, ABESS/CEDEPSS, 1997.

ABEPSS/CFESS/CRESS/ENESSO. Manifesto de entidades de Serviço Social contra cursos de graduação a distância para a formação de assistentes sociais. Dia do(a) Assistente Social, 15 de maio de 2008. Disponível em: $<$ http://www.abepss.org.br/>. Acesso em: jul. 2008.

BOSCHETTI, I. Desafios atuais da formação profissional: exame de proficiência e o ensino a distância. Disponível em: <www.cress 16.org.br/debateexameproeficiencia.doc $>$. Acesso em: jul. 2008.

BRASIL. Lei n. 9.393, de 20 de dezembro de 1996 Estabelece as diretrizes e bases da educação nacional. Disponível em: <http://www.presidencia.gov.br/CCIVIL/ LEIS/L9394.htm\#art44>. Acesso em: mar. 2006.

. INEP/MEC. Censo da Educação Superior 2004: Resumo técnico. Brasília, 2005. Disponível em: $<$ http:// www.inep.gov.br>. Acesso em: mar. 2006.

Ministério da Educação. Educação. 2008. Disponível em: <http://portal.mec.gov.br/sesu/index.php? option $=$ com_content $\&$ task $=$ view $\&$ id $=900>$. Acesso em: mar. 2008.

. INEP/MEC. Cadastro Nacional das Instituições

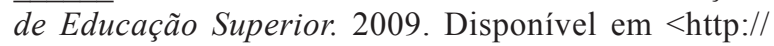
www.educacaosuperior.inep.gov.br/>. Acesso em: mar. 2009.

Censo da Educação Superior 2007: resumo técnico. Brasília, 2009a. Disponível em: <http:// www.inep.gov.br>. Acesso em: mar. 2009.

Censo da Educação Superior 2007: resultados das principais variáveis. Brasília, 2009b. Disponível em: <http://www.inep.gov.br/imprensa/ noticias/censo/superior/news09_01.htm>. Acesso em: mar. 2009.

. Universidade Aberta do Brasil. 2009c. Disponível em: $<$ http://uab.capes.gov.br/>. Acesso em: mar. 2009. 
BRESSER PEREIRA, L. C. Estratégia e estrutura para um novo Estado. Revista de Economia Política, v. 17, n. 3, 1997. Disponível em: <http://www.rep.org.br>. Acesso em: mar. 2006.

CHAUI, M. A universidade em ruínas. In: TRINDADE, $\mathrm{H}$. (Org.). Universidade em ruínas na república dos professores. Petrópolis, RJ: Vozes/Rio Grande do Sul: CIPEDES, 1999.

COUTINHO, C. N. Gramsci: um estudo sobre seu pensamento político. Rio de Janeiro: Campus, 1992.

Notas sobre cidadania e modernidade. Revista Ágora: Políticas Públicas e Serviço Social, ano 2, n. 03, 2005. Disponível em: <http://www.assistentesocial.com.br>. Acesso em: mar. 2006.

FOLHA ONLINE. Curso a distância para docente cresce $270 \%$ em 5 anos. Folha Online, nov. 2008, 10 h51. Disponível em: <http:/www1.folha.uol.com.br/folha/ educacao/ult305u463822.shtml>. Acesso em: mar 2009.

GRAMSCI, A. Cadernos do Cárcere: os intelectuais, o princípio educativo - jornalismo. Tradução de Carlos Nelson Coutinho. Rio de Janeiro: Civilização Brasileira, 2004. (v. 2).

HARVEY, D. Condição pós-moderna: uma pesquisa sobre as origens da mudança cultural. São Paulo: Loyola, 1992.

IAMAMOTO, M. V. Renovação e conservadorismo no Serviço Social. São Paulo: Cortez, 1996.

. Serviço Social em tempo de capital fetiche: capital financeiro, trabalho e questão social. São Paulo: Cortez, 2007. (v. 1).

IAMAMOTO, M. V.; CARVALHO, R. Relações sociais e Serviço Social no Brasil: esboço de uma interpretação histórico-metodológica. São Paulo: Cortez, 1995.

LESBAUPIN, Y. (Org.). O desmonte da nação: balanço do governo FHC. Rio de Janeiro: Vozes, 1999.

LEHER, R. Da ideologia do desenvolvimento à ideologia da globalização: a educação como estratégia do Banco Mundial para 'alívio' da pobreza. Tese (Doutorado) Faculdade de Educação da Universidade de São Paulo, 1998.

LIMA, K. R. de S. Contra-reforma da educação superior: de FHC a Lula. São Paulo: Xamã, 2007.

. Reforma da educação superior e educação a distância: democratização do acesso ou subordinação das instituições públicas de ensino superior à ordem do capital? Caderno especial n. 33. Edição 08 de Maio a 05 de Junho de 2006. Disponível em: <www.assistentesocial.com.br/ cadespecial33.pdf>. Acesso em: 20 abr. 2008.

LIMA, K. R. de S.; MARTINS, A. S. Pressupostos, princípios e estratégias. In: NEVES, L. (Org.). A nova pedagogia da hegemonia. São Paulo: Xamã, 2005.

MARE - Ministério de Administração e Reforma do Estado. Presidência da República. Plano Diretor da Reforma do Aparelho do Estado. Brasília, 1995. Disponível em: $<$ http:/ /www.presidencia.gov.br/publi_04/COLECAO/ PLANDI.htm>. Acesso em: mar. 2006.

McCOWAN, T. Perfil de seis empresas líderes em educação superior. Tema em Debate: Mercantilização do Ensino Superior. Disponível em: <http://www.lpp-uerj.net/olped>. Acesso em: jul. 2004.

MOTA, A. E. Cultura da crise e seguridade social: um estudo sobre as tendências da previdência e da assistência social brasileira nos anos 80 e 90. São Paulo: Cortez, 1995.

NEVES, L. M. W. (Org.). O empresariamento da educação: novos contornos do ensino superior no Brasil dos anos 1990. São Paulo: Xamã, 2002. (Coletivo de Estudos sobre Política Educacional).

(Org.). A nova pedagogia da hegemonia. São Paulo: Xamã, 2005.

OLIVEIRA, F. de Os direitos do antivalor: a economia política da hegemonia imperfeita. Petrópolis: Vozes, 1998.

PAUlO NETTO, J. Capitalismo monopolista e Serviço Social. São Paulo: Cortez, 1996a.

. Ditadura e Serviço Social - uma análise do Serviço Social no Brasil pós-64. São Paulo: Cortez, 1996b.

PEREIRA, L. D. Educação e Serviço Social: do confessionalismo ao empresariamento da formação profissional. São Paulo: Xamã, 2008a.

- Ensino superior e Serviço Social brasileiro: análise dos cursos de Serviço Social na modalidade de educação a distância. Niterói: Universidade Federal Fluminense/Escola de Serviço Social. Projeto de pesquisa, $2008 b$.

SAVIANI, D. A nova lei da educação: trajetória, limites e perspectivas. Campinas: Autores Associados, 1997. (Contemporânea).

UNESCO. Tendências da educação superior para o século XXI. In: CONFERÊNCIA MUNDIAL SOBREEDUCAÇÃO SUPERIOR, 1998, Paris. Anais... Brasília: Unesco/Crub, 1999a. 
Política de mudança e desenvolvimento no ensino superior. Rio de Janeiro: Garamond, 1999b.

UNIVERSIA. Espanha. Primeiro relatório mundial sobre a situação do ensino superior no mundo. Reportagem de 30/ 11/2005. Disponível em: <http://www.universia.es/ html_trad/portada/actualidad/noticia_actualidad_trad/ params/anyo/2005/mes/Noviembre/noticia/ieeii.html>. Acesso em: mar. 2009.

\section{Notas}

1 Sobrea "socialização da política", ver Coutinho(2005).

2 Compreendemos o processo de alargamento da cidadania atravessado pelas inúmeras lutas sociais, da classe trabalhadora, desencadeadas ao longo dos séculos 19 e 20: com isto, a cidadania estritamente liberal, baseada nos direitos civis, "alargou-se", conformando novos direitos (políticos e sociais)(COUTINHO, 2005).

3 O conceito de "Terceiro Setor" é uma construção ideológica, que concebe a sociedade organizada em setores (o Estado, o mercado e a sociedade civil), velando as contradições e conflitos entre as classes sociais.

4 McCowan (2004) aponta que os países periféricos (Ásia, América Latina e África) comportam as maiores proporções de alunos matriculados em instituições privadas de ensino superior e configuram-se enquanto mercados com grande potencial de expansão.

5 Sobre opapel dos organismos internacionais, cf. Leher(1998) eLima(2007).

6 Lesbaupin (1999) mostra o "desmonte da nação" operado na era FHC e Antunes (2004) analisa as continuidades e diferenças entre os governos Cardoso e Lula.

7 Cf.MARE(1995)e também Bresser Pereira(1997).

8 Para uma leitura crítica da "questão social", cf. Iamamoto (2007).

9 Para Gramsci (2004), o intelectual não se resume à atividade intelectual, pois todos os homens são intelectuais e têm a capacidade de realizar atividades intelectivas. O intelectual é aquele que organiza e educa, istoé, tem a função de dirigente, de difusão da concepção de mundo da classe dominante e de manutenção do consenso em relação à ordem estabelecida. O intelectual, contudo, também pode ser orgânico à classe subalterna e contribuir para difundir uma concepção de mundo contra-hegemônica. Cf. Coutinho(1992).

10 Cf. análises de Lima(2007)eNeves (2002; 2005).
11 De acordo com a legislação vigente, as universidades devem realizar atividades de ensino, pesquisa e extensão, contar com $1 / 3$ de doutores e mestres em seu quadro docente e com $1 / 3$ de seus professores contratados em regime de tempo integral(BRASIL, 1996, art. 52).

12 Sobre a análise da política educacional no governo FHC, cf. Lima(2007)ePereira(2008a).

13 “Criado pelo Governo Federal em 2004, o ProUni tem como finalidade a concessão de bolsas de estudos integrais e parciais, a estudantes de cursos de graduação e sequenciais de formação específica, em instituições privadas de educação superior. Em contrapartida, o programa oferece isenção de tributos às Instituições que aderem." Texto de apresentação do ProUni, retirado da página virtual do Ministério da Educação(BRASIL, 2008, online).

14 Demanda que o setor privado rapidamente percebe. Porém, a maior parte da população não tem condições de custear seus estudos de forma privada: um dado que explicita esta situação é o de vagas ociosas apresentadas pelo Censo da Educação Superior de 2007. Neste censo, foram registradas 1.341.987 vagas ociosas, sendo, destas, 1.311.218 pertencentes às IES privadas (INEP/MEC, 2009). O ProUni claramente veio "apoiar" estas IES a preencher suas vagas.

15 Principalmente quando a política governamental opta por proporcionar isenção fiscal ao setor privado - através do ProUni - ao invés de ampliar o mesmo número de vagas na rede pública.

16 Contudo, de acordo com informações disponíveis na página da UAB (BRASIL, 2009d, online, grifos da autora), "[...] os cursos oferecidos no Sistema UAB são ofertados por instituições públicas de ensino superior, portanto, são gratuitos. No entanto, as instituições 'podem cobrar taxas dematrículas.".

17 Há uma larga legislação sobre EaD que não será analisada aqui. Contudo, é importante lembrar que a Lei de Diretrizes e Bases daEducação Nacional(LDB), de 1996(BRASIL, 1996), deu a "chancela" legal para o incentivo governamental à difusão da educação a distância, o que foi realizado e focado na formação de professores. Cf. Saviani (1997). Cf. também matéria da Folha Online (2008), que afirma a existência em 2008, de acordo com o Ministério da Educação, de um déficit de 246 mil docentes no país.

18 Cf. o detalhamento da criação das Escolas de Serviço Social, articulado à política educacional de cada período histórico brasileiro: Pereira(2008a).

19 Para uma aproximação crítica à história do Serviço Social no Brasil,cf. Iamamotoe Carvalho(1995); Iamamoto(1996); Paulo Netto(1996a; 1996b). 
20 Sobre o processo de renovação profissional, cf. Paulo Netto (1996b).

21 Considerou-se os cursos existentes até 1994-o que totalizou 74ESSs - como possíveis participantes dos debates. Aqueles autorizados e/ou em início de funcionamento entre 1994 e 1996 provavelmente não participaram dos debates promovidos pelaABEPSS.

22 Os dados do Cadastro das IES(BRASIL, 2009), relativos aos cursos de Serviço Social na modalidade a distância, são atualizados de forma permanente por esta autora e pela equipe de iniciação científica - alunas da ESS/UFF - inseridas na pesquisa em curso: Aline Teles Veloso Coelho (bolsista/ FAPERJ), Juliana Falcão Carino (bolsista PROAC/UFF), Rafaela Vieira (bolsista PROAC/UFF), TaianeAlecrim Matos (PIBIC/CNPq) e Tereza Cristina Machado Faria (bolsista $\mathrm{PROAC/UFF).}$

23 Da totalidade de cursos presenciais de Serviço Social, somente dois não disponibilizam a informação quanto ao número de vagas (INEP/MEC, 2009).

24 Vale ressaltar que os desafios já estão postos. Cf. nota do conjunto de entidades da categoria: ASSOCIAÇÃO BRASILEIRADEENSINOEPESQUISAEM SERVIÇO SOCIAL, CONSELHOFEDERALDESERVIÇOSOCIAL, CONSELHOS REGIONAIS DE SERVIÇO SOCIAL, EXECUTIVA NACIONAL DOS ESTUDANTES DE SERVIÇO SOCIAL(ABEPSS/CFESS/CRESS/ENESSO, 2008).

\section{Larissa Dahmer Pereira}

larissadahmer@hotmail.com

Doutorado em Serviço Social pelo Programa de PósGraduação em Serviço Social da Universidade Federal do Rio de Janeiro (UFRJ)

Docente da Escola de Serviço Social da Universidade Federal Fluminense (ESS/UFF)

\section{Universidade Federal Fluminense, Escola de Serviço Social}

Campus do Gragoatá - Bloco E

São Domingos

Niterói - Rio de Janeiro - Brasil

CEP: 24210-350 